\title{
Loss of interest, depressed mood and impact on the quality of life: Cross-sectional survey
}

Valeri D Guajardo', Bruno PF Souza', Sérgio G Henriques', Mara CS Lucia², Paulo R Menezes ${ }^{3}$, Milton A Martins ${ }^{4}$, Leila SLPC Tardivo ${ }^{5}$, Wagner F Gattaz ${ }^{1}$ and Renério Fráguas ${ }^{1 *}$

\begin{abstract}
Background: Depressive symptoms and chronic disease have adverse effects on patients' health-related quality of life $(\mathrm{H}-\mathrm{RQOL})$. However, little is known about this effect on $\mathrm{H}-\mathrm{RQOL}$ when only the two core depressive symptoms - loss of interest and depressed mood - are considered. The objective of this study is to investigate H-RQOL in the presence of loss of interest and depressed mood at a general medical outpatient unit.

Methods: We evaluated 553 patients at their first attendance at a general medical outpatient unit of a teaching hospital. H-RQOL was assessed with the Medical Outcomes Study 36-item Short-Form Health Survey (SF-36). Depressed mood and loss of interest were assessed by the Primary Care Evaluation of Mental Disorders (PRIME-MD)Patient Questionnaire. A physician performed the diagnosis of chronic diseases by clinical judgment and classified them in 13 possible pre-defined categories. We used multiple linear regression to investigate associations between each domain of $\mathrm{H}-\mathrm{RQOL}$ and our two core depression symptoms. The presence of chronic diseases and demographic variables were included in the models as covariates.

Results: Among the 553 patients, 70.5\% were women with a mean age of 41.0 years (range 18-85, SD \pm 15.4 ). Loss of interest was reported by $54.6 \%$, and depressed mood by $59.7 \%$ of the patients. At least one chronic disease was diagnosed in $59.5 \%$ of patients; cardiovascular disease was the most prevalent, affecting $20.6 \%$ of our patients. Loss of interest and depressed mood was significantly associated with decreased scores in all domains of H-RQOL after adjustment for possible confounders. The presence of any chronic disease was associated with a decrease in the domain of vitality. The analysis of each individual chronic disease category revealed that no category was associated with a decrease in more than one domain of $\mathrm{H}-\mathrm{RQOL}$.
\end{abstract}

Conclusion: Loss of interest and depressed mood were associated with significant decreases in H-RQOL. We recommend these simple tests for screening in general practice.

\section{Background}

Depression is an important public health problem associated with impairment in quality of life, high levels of disability, increased medical comorbidity and mortality rates $[1,2]$. In primary care, major depression has a high prevalence ranging from $2.6 \%$ to $29.5 \%$, according to epidemiological studies [3-5].

The Medical Outcomes Study highlighted the evidence of the adverse effects of depression on patient functional status and well-being [6,7], and various studies have

\footnotetext{
* Correspondence: fraguasr@gmail.com

'Department of Psychiatry, Institute of Psychiatry of Clinics Hospital Faculty of Medicine University of Sao Paulo, (Rua Dr. Ovídio Pires de Campos, 785 $3^{\circ}$ andar - sala 13), Sao Paulo, (CEP: 05403-010), Brazil

Full list of author information is available at the end of the article
}

reported the relevant impairment of health-related quality of life (H-RQOL) associated with depression [8-10].

Actually, there is a close association between depression and various domains of H-RQOL [11]; depression has been associated with a decrease in experiencing positive well-being [12], impairment in role functioning [13] and disabilities in social functioning [14]. In fact, several studies show a reduction of H-RQOL in patients suffering from depression as compared with the general population $[15,16]$, as well as with patients with chronic diseases $[6,15]$. It has also been reported that depressed patients have more substantial and longer-lasting decrements in multiple domains of functioning and well-being than patients with chronic diseases [17]. 
Depression is frequently associated with chronic disease with a reported 12-month prevalence among patients with chronic disease ranging from $7.9 \%$ to $17 \%$ [18]. Major depression in patients with chronic disease has been associated with increased symptom burden, which leads to functional impairment, self-care impairment [19], diminished adherence to treatment, undermined general perception of health and reduced levels of energy, social interaction and motivation, consequently decreasing H-RQOL [20]. Studies have shown that chronic diseases can be debilitating and affect a patient's behavior, mood, work capacity, and vital functions, such as ambulation, mobility and the capacity to perform daily activities and eventually H-RQOL $[21,22]$. These associations are relevant because chronic disease may potentially work as a confounding variable in studies focusing on the negative impact of depression on H-RQOL.

Lately, there has been increased interest in the development, validation and clinical utilization of quick screening and brief scales for depression [23-27]. According to this approach, previous studies have supported that two symptoms, depressed mood and anhedonia (loss of interest), may be enough for detecting depression in primary care [23]. In line with this approach, the aim of our study was to investigate the association between two core symptoms of depression (loss of interest and depressed mood) and H-RQOL in general medical patients taking into account the presence of comorbid chronic disease.

\section{Methods}

\section{Setting}

A cross-sectional survey was conducted in a general internal medicine outpatient unit of a teaching hospital (Ambulatório Geral e Didático da Clínica Médica do Hospital das Clínicas, University of Sao Paulo School of Medicine; AGD - HC-FMUSP) [28,29]. This unit accepts patients from a catchment area of the city of São Paulo and patients referred by other services. Candidate patients are submitted to a screening interview and those with established severe medical conditions are usually referred to an appropriated specialized outpatient unit. During the period from 1998 to 2000, 587 consecutive patients going through their first attendance in that unit were assessed.

\section{Study population}

We included patients of both genders, aged 18 years or older that were going through their first attendance in this hospital's unit. Patients unable to communicate, with severe cognitive deficits or unable to participate in the interview were excluded. We excluded 34 patients because of incomplete data. The remaining 553 patients formed the sample of this study.
Patients were evaluated from Monday to Friday during the morning and afternoon. They were approached and informed about the scope of the interview. The patients that agreed to participate had to read and sign the written consent.

This study was approved and carried out in accordance with ethical standards set by the Ethics Committee of the HC-FMUSP and the Department of Psychiatry, Faculty of Medicine of the University of Sao Paulo.

\section{Questionnaire}

Health-related quality of life was assessed by the Medical Outcomes Study item-36 Short-Form Health Survey (SF36) designed by Ware and Sherboune [30] and validated for the Brazilian-Portuguese by Ciconelli [31]. This questionnaire evaluates the state of physical and mental health individually. The questionnaire consists of 36 items and covers eight domains: physical functioning (PF), role limitations due to physical problems (RP), bodily pain $(\mathrm{BP})$, general health $(\mathrm{GH})$, vitality $(\mathrm{VT})$, social functioning (SF), role limitations due to emotional problems (RE) and mental health (MH). The scores vary from 0 to 100 , and a lower score is associated with a worse perception of health, loss of function and presence of pain, and a higher score is associated with a good perception of health, preserved function and no pain.

The SF-36 was designed to be a self-administered instrument, but it can be applied with the assistance of a trained person. In this study, the patient answered the questions in the waiting room assisted by a psychologist.

The assessment of loss of interest and depressed mood were assessed by questions 17 and 18 from the Patient's Questionnaire of Prime-Md (QP), which corresponds to loss of interest in routine activities and depressed mood, respectively [29].

The assessment of morbidity was performed by clinicians who filled a questionnaire with yes/no answers for the presence of chronic diseases. Using clinical judgment, clinicians classified the diseases according to 13 predefined categories of disease, including cardiovascular, infectious, endocrine, neurological, rheumatological, gastrointestinal, psychiatric, dermatological, orthopedic, gynaecological, oncological, allergic/immunological or other chronic diseases.

\section{Statistical methods}

The SF-36 scores were calculated according to the established scoring algorithms for the Brazilian version of the SF-36 [31]. The assessment of anhedonia, depressed mood and chronic diseases were reported as absent or present. In addition, the sample was analyzed in three groups including those without chronic disease $(n=225)$, those with one chronic disease $(n=260)$ and those with 
two or more chronic diseases $(n=68)$ to investigate a potential gradient effect.

We used multiple linear regression to investigate associations between each domain of H-RQOL and our two core depression symptoms. The presence of chronic diseases and demographic variables were included in the models as covariates.

The confidence interval was $95 \%$ and significance level was set at $\mathrm{p} \leq .05$. All statistical analyses were carried out using SPSS for Windows (version 15.0; SPSS Inc., Chicago, IL, USA).

\section{Results}

Among the 553 patients, $70.5 \%$ were women and the mean age was 41.0 years (range $18-85, \mathrm{SD} \pm 15.4$ ). The assessment of depressive symptoms showed that $54.6 \%$ of the patients presented loss of interest and $59.7 \%$ presented depressed mood. A total of 329 (59.5\%) patients had at least one of the thirteen categories of chronic diseases, with cardiovascular the most common affecting 114 (20.6\%) patients. The demographic characteristics of the sample are shown in Table 1.

The mean values obtained by the whole sample in SF36 are listed in Table 2. RP had the lowest score (mean = 32.6) while PF had the highest ( mean $=65$ ).

Table 3 shows the univariate analysis with means values and association of domains of SF-36 with presence or absence of loss of interest, depressed mood and chronic diseases. The presence of loss of interest and depressed mood were significantly associated with all domains of the SF-36, while the presence of chronic diseases was associated with a decrease in the domain vitality. In the investigation of a potential gradient effect of chronic disease, the group without chronic diseases showed significantly better scores in the domains PF, $\mathrm{RP}, \mathrm{VT}$ and RE. The group with one chronic disease was significantly associated with lower scores in VT and the group with two or more chronic disease was significantly associated with lower scores in PF, RP and GH. The results of the multi-variable linear regression are shown in Table 4, which show the constant for each domain of H-RQOL for the all sample and the respective changes for each variable. Loss of interest was associated to a reduction of 7.4 points in PF's score, 26.7 points in RP, 8.8 points in BP, 9.3 points in $\mathrm{GH}, 15.3$ points in VT, 18.9 in SF, 17.6) in RE and 11.7 points in MH. Depressed mood showed association with a decrease of 6.6 points in PF's score, 9.8 points in RP, 8.6 points in BP, 13.2 points in $\mathrm{GH}, 15.1$ points in VT, 15.9 points in SF, 19.4 points in RE and 23.4 points in $\mathrm{MH}$. The presence of a chronic disease was associated with a decrease of 4.6 points in VT's score. This analysis showed that male sex was significantly associated with higher scores in PF, RP, BP, VT and MH. Patients with
Table 1 Demographics, characteristics and prevalence of depressive symptoms and chronic disease

\begin{tabular}{ll}
\hline Characteristics & \\
\hline Age (M \pm SD) & $41.0 \pm 15.4$ \\
Gender & \\
Female, n (\%) & $390(70.5)$ \\
Male, n (\%) & $163(29.5)$ \\
& \\
Marital status, $\mathbf{n}(\%)$ & $133(24.1)$ \\
Single & $281(50.8)$ \\
Married & $57(10.3)$ \\
Divorced & $40(7.2)$ \\
Widowed & $42(7.6)$ \\
No information &
\end{tabular}

Depressive symptoms, $\mathbf{n}(\%)$

Loss of interest $\quad 302(54.6)$

Depressed mood $\quad 330(59.7)$

Chronic Disease, n (\%) 329 (59.5)

Cardiovascular $114(20.6)$

Infectious $\quad 10(1.8)$

Endocrine $\quad 45$ (8.1)

Neurological $29(5.2)$

Rheumatological $25(4.5)$

Gastrointestinal $\quad 42(7.5)$

Psychiatric $\quad 12(2.1)$

Dermatological 20 (3.6)

Orthopedic 19 (3.4)

Gynaecological $\quad 16(2.8)$

Oncological $3(0.3)$

Allergic/Immune $\quad 26(4.7)$

Other chronic diseases $\quad 55$ (9.9)

M: mean; SD: standard deviation.

Table 2 Domains of SF-36

\begin{tabular}{lc}
\hline Domains of SF-36 & M \pm SD \\
\hline PF & $65.0 \pm 26.5$ \\
RP & $32.6 \pm 40.2$ \\
BP & $42.5 \pm 25.7$ \\
GH & $57.4 \pm 24.5$ \\
VT & $44.3 \pm 23.8$ \\
SF & $64.9 \pm 30.0$ \\
RE & $43.2 \pm 42.8$ \\
MH & $48.8 \pm 24.7$ \\
\hline
\end{tabular}

M: mean; SD: standard deviation; SF-36: Short Form Health Survey. PF: physical functioning; RP: role functioning physical; BP: bodily pain; GH: general health perceptions; VT: vitality; SF: social functioning; RE: emotional role functioning; $\mathrm{MH}$ : mental health 
Table 3 Mean values and association of domains of SF-36 with presence or absence of depressive symptoms and chronic disease

\begin{tabular}{|c|c|c|c|c|c|c|c|c|}
\hline & $\mathrm{PF}$ & $\mathrm{RP}$ & BP & GH & VT & SF & $\mathrm{RE}$ & $\mathrm{MH}$ \\
\hline All sample $(\mathrm{M} \pm \mathrm{SD})$ & $64.8 \pm 26.5$ & $32.6 \pm 40.2$ & $42.5 \pm 25.7$ & $57.4 \pm 24.5$ & $44.3 \pm 23.8$ & $64.8 \pm 30.1$ & $43.2 \pm 42.8$ & $49.7 \pm 24.7$ \\
\hline $\begin{array}{l}\text { Loss of interest ( } 95 \% \\
\text { Cl) }\end{array}$ & $\begin{array}{c}59.7 \pm 25.8 \\
{[6.7 ; 15.5]}\end{array}$ & $\begin{array}{c}18.5 \pm 31.4 \\
{[24.7 ; 37.5]}\end{array}$ & $\begin{array}{c}36.7 \pm 23.5 \\
{[8.5 ; 17.0]}\end{array}$ & $\begin{array}{c}50.8 \pm 23.5 \\
{[10.5 ; 18.3]}\end{array}$ & $\begin{array}{c}34.6 \pm 19.6 \\
{[17.8 ; 25.0]}\end{array}$ & $\begin{array}{c}53.6 \pm 29.3 \\
{[20.1 ; 29.2]}\end{array}$ & $\begin{array}{c}31.5 \pm 39.4 \\
{[18.9 ; 32.7]}\end{array}$ & $\begin{array}{c}39.4 \pm 21.3 \\
{[16.8 ; 24.4]}\end{array}$ \\
\hline $\begin{array}{l}\text { Without loss of } \\
\text { interest }(95 \% \mathrm{Cl})\end{array}$ & $\begin{array}{c}70.9 \pm 26.2 \\
{[6.7 ; 15.4]}\end{array}$ & $\begin{array}{c}49.7 \pm 43.0 \\
{[24.9 ; 37.3]}\end{array}$ & $\begin{array}{c}49.5 \pm 26.5 \\
{[8.6 ; 16.9]}\end{array}$ & $\begin{array}{c}65.3 \pm 23.3 \\
{[10.5 ; 18.3]}\end{array}$ & $\begin{array}{c}56.0 \pm 23.2 \\
{[17.8 ; 25.0]}\end{array}$ & $\begin{array}{c}78.3 \pm 25.2 \\
{[20.0 ; 29.2]}\end{array}$ & $\begin{array}{c}57.3 \pm 42.6 \\
{[18.9 ; 32.7]}\end{array}$ & $\begin{array}{c}60.0 \pm 23.9 \\
{[16.8 ; 24.4]}\end{array}$ \\
\hline $\begin{array}{l}\text { Depressed mood ( } 95 \% \\
\text { Cl) }\end{array}$ & $\begin{array}{c}60.5 \pm 26.2 \\
{[6.2 ; 15.1]}\end{array}$ & $\begin{array}{c}24.2 \pm 35.7 \\
{[14.0 ; 27.8]}\end{array}$ & $\begin{array}{c}37.0 \pm 23.3 \\
{[9.2 ; 18.0]}\end{array}$ & $\begin{array}{c}50.5 \pm 23.8 \\
{[13.1 ; 20.8]}\end{array}$ & $\begin{array}{c}35.6 \pm 20.5 \\
{[17.8 ; 25.3]}\end{array}$ & $\begin{array}{c}55.4 \pm 29.7 \\
{[18.5 ; 27.7]}\end{array}$ & $\begin{array}{c}32.4 \pm 39.4 \\
{[19.8 ; 33.9]}\end{array}$ & $\begin{array}{c}37.3 \pm 19.8 \\
{[24.9 ; 32.0]}\end{array}$ \\
\hline $\begin{array}{l}\text { Without depressed } \\
\text { mood }(95 \% \mathrm{Cl})\end{array}$ & $\begin{array}{l}71.2 \pm 25.9 \\
{[6.2 ; 15.1]}\end{array}$ & $\begin{array}{c}45.1 \pm 43.1 \\
{[14.3 ; 27.5]}\end{array}$ & $\begin{array}{c}50.7 \pm 27.0 \\
{[9.4 ; 17.9]}\end{array}$ & $\begin{array}{c}67.5 \pm 21.9 \\
{[13.0 ; 20.8]}\end{array}$ & $\begin{array}{c}57.2 \pm 22.7 \\
{[17.9 ; 25.2]}\end{array}$ & $\begin{array}{c}78.6 \pm 24.8 \\
{[18.4 ; 27.9]}\end{array}$ & $\begin{array}{c}59.3 \pm 42.6 \\
{[19.9 ; 33.8]}\end{array}$ & $\begin{array}{c}65.7 \pm 21.3 \\
{[25.0 ; 31.9]}\end{array}$ \\
\hline $\begin{array}{l}\text { Chronic disease }(95 \% \\
\mathrm{Cl})\end{array}$ & $\begin{array}{c}61.0 \pm 26.6 \\
{[5.0 ; 13.8]}\end{array}$ & $\begin{array}{c}28.5 \pm 39.4 \\
{[3.3 ; 16.9]}\end{array}$ & $\begin{array}{c}42.1 \pm 25.9 \\
{[-3.2 ; 5.5]}\end{array}$ & $\begin{array}{c}56.0 \pm 23.3 \\
{[-0.7 ; 7.7]}\end{array}$ & $\begin{array}{c}41.8 \pm 23.2 \\
{[2.0 ; 10.1]}\end{array}$ & $\begin{array}{c}63.5 \pm 30.8 \\
{[-1.9 ; 8.1]}\end{array}$ & $\begin{array}{c}40.1 \pm 41.9 \\
{[0.4 ; 15.1]}\end{array}$ & $\begin{array}{l}48.2 \pm 24.8 \\
{[-2.7 ; 5.6]}\end{array}$ \\
\hline $\begin{array}{l}\text { Without chronic } \\
\text { disease }(95 \% \mathrm{Cl})\end{array}$ & $\begin{array}{c}70.4 \pm 25.4 \\
{[5.0 ; 13.9]}\end{array}$ & $\begin{array}{c}38.7 \pm 40.6 \\
{[3.3 ; 16.9]}\end{array}$ & $\begin{array}{l}43.2 \pm 25.5 \\
{[-3.2 ; 5.5]}\end{array}$ & $\begin{array}{c}59.5 \pm 26.0 \\
{[-0.6 ; 7.6]}\end{array}$ & $\begin{array}{c}47.9 \pm 24.4 \\
{[2.0 ; 10.1]}\end{array}$ & $\begin{array}{c}66.6 \pm 29.0 \\
{[-1.9 ; 8.2]}\end{array}$ & $\begin{array}{c}47.9 \pm 43.8 \\
{[0.5 ; 15.0]}\end{array}$ & $\begin{array}{c}49.6 \pm 24.7 \\
{[-2.7 ; 5.6]}\end{array}$ \\
\hline
\end{tabular}

The values shown represent the mean, standard deviation and confidence interval (95\% CI). M: mean; SD: standard deviation; SF-36: Short Form Health Survey. PF: physical functioning; RP: role functioning physical; BP: bodily pain; GH: general health perceptions; VT: vitality; SF: social functioning; RE: emotional role functioning; $\mathrm{MH}$ : mental health.

age $>65$ years had the highest RE scores, and single patients presented the highest scores in PF, RP and RE.

\section{Discussion}

In this study of 553 general practice outpatients, we found associations between decreased H-RQOL and two simple screening measures for depression (loss of interest and depressed mood). Both symptoms were independently associated with lower scores on all subscales of the SF-36. These results are consistent with past reports of the association between depression and H-RQOL $[8,19,32]$. Previous studies have investigated the association of H-RQOL with depressive symptoms' scales or with the diagnosis of depression. On this point, our study differs in that we investigated whether only two selfreported screening symptoms for depression were associated with decreased H-RQOL. Because the evaluation of loss of interest and depressed mood are quick, inexpensive and non-invasive and, as shown by our study, are significantly associated with low H-RQOL, we suggest they are useful indicators of $\mathrm{H}-\mathrm{RQOL}$ in general practice.

Our data reinforce previous studies supporting the use of these two symptoms in screening for major depressive disorder among medical patients. One study with multiple sclerosis patients found that the presence of these two symptoms could identify almost all patients with major depressive disorder, with minimal numbers of false positive [24]. Another study that used the Beck Depression Inventory II (BDI-II) to detect major depressive disorder, concluded that one or two questions regarding sadness and loss of interest serve as simple and effective screening tools for depression post-acute myocardial infarction [33].

An intriguing point of our results is the association of depressed mood and loss of interest with the various domains of the SF-36. Previous studies have reported impaired quality of life in patients with depression, especially when compared to the general population and patients with other chronic diseases [34], such as diabetes, arthritis or cardiovascular disease $[6,8,17,35]$. It should be noted that the SF-36 includes two domains, the physical one formed by PF, RP, BP and GH and the mental one formed by VT, SF, RE and MH. If we apply this reasoning, our data revealed that the two depressive symptoms affect both the physical and the mental domains, while chronic diseases affect almost exclusively the physical domains. Similar results were described in a study of patients with differing chronic diseases in Germany that compared the $\mathrm{H}$-RQOL in patients of general practice with the general population [22]. Actually, in our study, no specific chronic disease affected more than one domain of SF-36. A similar pattern has been reported by a Chinese study, in which the presence of a chronic disease was associated with impairment of some but not all domains of H-RQOL [36]. The main difference between these studies and ours is that we focused only on two depressive symptoms.

Approximately seventy percent of patients visiting the AGD are female and this proportion is similar to other studies that assessed the H-RQOL in primary care such as Fleck et al (2002) [32] (79.5\%) and Schwenk et al (1996) [37] (79.8\%). Women's higher demand for the health service in our study may have been influenced by the association found between depressed mood and female gender ( $p=0.02)$, since there wasn't any association between chronic disease and gender. Alternatively, it is possible that the increased demand by women for health services is related to their decreased H-RQOL in five of the eight domains of the SF-36, PF, RP, BP, VT and $\mathrm{MH}$, but we cannot establish a causality due to the cross-sectional nature of our study. 
Table 4 Multiple linear regressions for the association of domains of SF-36 with depressive symptoms, clinical and socio-demographic variables

\begin{tabular}{|c|c|c|c|c|c|c|c|c|}
\hline & $\mathrm{PF}$ & $\mathrm{RP}$ & BP & GH & VT & SF & $\mathrm{RE}$ & $\mathrm{MH}$ \\
\hline Constant & 70.9 & 47.4 & 49.0 & 70.7 & 62.9 & 85.4 & 60.6 & 67.4 \\
\hline Gender $(95 \% \mathrm{Cl})$ & $\begin{array}{l}+8.8^{* * *} \\
{[4.4 ; 13.2]}\end{array}$ & $\begin{array}{c}+7.0^{*} \\
{[0.4 ; 13.7]}\end{array}$ & $\begin{array}{l}+10.8^{* * *} \\
{[6.4 ; 15.2]}\end{array}$ & - & $\begin{array}{c}+6.7^{* * *} \\
{[3.1 ; 10.4]}\end{array}$ & - & - & $\begin{array}{l}+5.8^{* *} \\
{[2.2 ; 9.4]}\end{array}$ \\
\hline $\begin{array}{l}\text { Categorized age } 1 \text { (18- } \\
24 \text { years) }\end{array}$ & - & - & - & - & - & - & - & - \\
\hline $\begin{array}{l}\text { Categorized age } 2 \text { ( } 25- \\
44 \text { years) }\end{array}$ & - & - & - & - & - & - & - & - \\
\hline $\begin{array}{l}\text { Categorized age } 3 \text { ( } 45 \text { - } \\
64 \text { years) }\end{array}$ & - & - & - & - & - & - & - & - \\
\hline $\begin{array}{l}\text { Categorized age } 4 \text { (>65 } \\
\text { years) }\end{array}$ & - & - & - & - & - & - & +9.8 & - \\
\hline Single $(95 \% \mathrm{Cl})$ & $\begin{array}{c}+14.9^{* * *} \\
{[10.3 ; 19.5]}\end{array}$ & $\begin{array}{l}+14.7^{* * *} \\
{[7.6 ; 21.8]}\end{array}$ & - & - & - & - & $\begin{array}{l}+12.3^{* *} \\
{[4.4 ; 20.1]}\end{array}$ & - \\
\hline Loss of interest $(95 \% \mathrm{Cl})$ & $\begin{array}{c}-7.4^{* *}[-11.6 ;- \\
3.1]\end{array}$ & $\begin{array}{c}-26.7^{* * *} \\
{[-33.2 ;-20.1]}\end{array}$ & $\begin{array}{c}-8.8^{* * *} \\
{[-13.1 ;-4.5]}\end{array}$ & $\begin{array}{c}-9.3^{* * *} \\
{[-13.3 ;-5.2]}\end{array}$ & $\begin{array}{l}-15.3^{* * *} \\
{[-18.8 ;-11.7]}\end{array}$ & $\begin{array}{c}-18.9^{* * *} \\
{[-23.7 ;-14.1]}\end{array}$ & $\begin{array}{c}-17.6^{* * *} \\
{[-24.8 ;-10.4]}\end{array}$ & $\begin{array}{c}-11.7^{* * *} \\
{[-15.2 ;-8.1]}\end{array}$ \\
\hline $\begin{array}{l}\text { Depressed mood (95\% } \\
\text { Cl) }\end{array}$ & $\begin{array}{c}-6.6^{* *}[-11.0 ;- \\
2.3]\end{array}$ & $\begin{array}{c}-9.8^{* *}[-16.5 ;- \\
3.1]\end{array}$ & $\begin{array}{c}-8.6^{* * *} \\
{[-13.1 ;-4.2]}\end{array}$ & $\begin{array}{c}-13.2^{* * *} \\
{[-17.3 ;-9.0]}\end{array}$ & $\begin{array}{l}-15.1^{* * *} \\
{[-18.8 ;-11.5]}\end{array}$ & $\begin{array}{c}-15.9^{* * *} \\
{[-20.7 ;-11.0]}\end{array}$ & $\begin{array}{c}-19.4^{* * *} \\
{[-26.7 ;-12.1]}\end{array}$ & $\begin{array}{c}-23.4^{* * *} \\
{[-27.0 ;-19.8]}\end{array}$ \\
\hline $\begin{array}{l}\text { Chronic disease }(95 \% \\
\text { Cl) }\end{array}$ & - & - & - & - & $\begin{array}{l}-4.6^{* *}[-8.0 ;- \\
1.2]\end{array}$ & - & - & - \\
\hline $\begin{array}{l}\text { Cardiovascular disease } \\
(95 \% \mathrm{Cl})\end{array}$ & $\begin{array}{c}-12.1^{* * *} \\
{[-17.0 ;-7.2]}\end{array}$ & - & - & - & - & - & & - \\
\hline $\begin{array}{l}\text { Endocrine disease }(95 \% \\
\text { Cl) }\end{array}$ & - & - & $\begin{array}{c}+10.7^{* *} \\
{[3.4 ; 18.0]}\end{array}$ & - & - & - & & - \\
\hline $\begin{array}{l}\text { Rheumatological } \\
\text { disease }(95 \% \mathrm{Cl})\end{array}$ & - & - & $\begin{array}{c}-12.4^{*} \\
{[-22.1 ;-2.8]}\end{array}$ & - & - & - & - & - \\
\hline $\begin{array}{l}\text { Psychiatric disease (95\% } \\
\mathrm{Cl})\end{array}$ & - & - & - & $\begin{array}{c}-14.9^{*}[-27.9 ;- \\
1.9]\end{array}$ & - & - & - & - \\
\hline $\begin{array}{l}\text { Dermatological disease } \\
(95 \% \mathrm{Cl})\end{array}$ & - & - & - & - & - & $\begin{array}{c}-15.2^{*}[-27.0 ;- \\
3.3]\end{array}$ & - & - \\
\hline $\begin{array}{l}\text { Orthopedic disease } \\
(95 \% \mathrm{Cl})\end{array}$ & - & - & - & - & $\begin{array}{c}-11.4^{*}[-20.6 ;- \\
2.2]\end{array}$ & - & - & - \\
\hline $\begin{array}{l}\text { Gynaecological disease } \\
(95 \% \mathrm{Cl})\end{array}$ & $\begin{array}{c}-17.1^{* *} \\
{[-28.9 ;-5.2]}\end{array}$ & - & - & - & - & - & - & - \\
\hline $\begin{array}{l}\text { Oncological disease } \\
(95 \% \mathrm{Cl})\end{array}$ & $\begin{array}{c}-39.9 * * \\
{[-66.7 ;-13.1]}\end{array}$ & - & - & - & - & - & - & - \\
\hline $\begin{array}{l}\text { Other chronic diseases } \\
(95 \% \mathrm{Cl})\end{array}$ & $\begin{array}{c}-11.1^{* *} \\
{[-17.7 ;-4.5]}\end{array}$ & - & - & - & & - & - & - \\
\hline
\end{tabular}

The values shown represent the regression coefficient and confidence interval ( $95 \% \mathrm{Cl}$ ). One equation was constructed for each domain of SF-36 as the dependent variable and the depressive symptom, clinical and socio-demographic variable as the independent variable. Each equation was adjusted for variables found to be associated with the respective domain in the bi-variate analysis. PF: physical functioning; RP: role functioning physical; BP: bodily pain; GH: general health perceptions; VT: vitality; SF: social functioning; RE: emotional role functioning; MH: mental health.* $P<0.05,{ }^{* *} P<0.01, * * * P<0.001$.

In our sample, $12 \%$ of the patients visiting the AGD had more than one of the thirteen chronic diseases. This prevalence was relatively low compared with those reported in the literature. The proportion of multi-morbidity (two or more medical conditions) in general practice patients varies in previous studies with Wang et al (2008) [22] reporting it in 20\%, van den Akker et al (1998) [38] in $29.7 \%$ and Lam and Lauder (2000) [36] in $41 \%$ of the population under study. However, it is difficult to compare these studies because of many differences in methodology, target population, and the number and type of the diseases under study.

Some limitations of our study should be considered. The assessment of chronic disease was made by clinical judgment without validated instruments, and this might have introduced bias into our results. Furthermore, the severity of the chronic diseases was not assessed. However, we performed our analyses using three groups, those without chronic disease, those with one chronic disease and those with two or more chronic disease. In this analysis we found a gradient effect showing that those with two or more chronic disease presented with lower scores in PF, RP and GH while those with one chronic disease presented with lower scores only in VT. Although a gradient effect could be supported, it should be noted that even for those with two or more chronic disease the association with lower scores on H-RQOL was not as pervasive as it was for depressed mood and 
loss of interest. In addition, this study did not evaluate the impact of the treatment of depression on H-RQOL. It is also appropriate to mention that this was a cross-sectional study and cannot establish causality between associations. Last, while the study suggests that loss of interest and depressed mood are indicative of low $\mathrm{H}$ RQL, it should be remembered that these items are not sufficient to diagnose clinical depression and cannot replace a comprehensive clinical assessment of mood in the context of chronic disease.

\section{Conclusion}

This study indicates that loss of interest and depressed mood are associated with decreased H-RQOL. Loss of interest and/or depressed mood were associated with lower scores in all eight domains of SF-36, while each chronic disease affected no more than one domain of $\mathrm{H}$ RQOL. These findings are relevant because they show how loss of interest and/or depressed mood might affect H-RQOL.

This study also suggests that the assessment of loss of interest and depressed mood would be useful as a screening for low $\mathrm{H}$-RQOL, since these two questions are quick, inexpensive and the presence of at least one of these symptoms has a significant association with reduced scores in all domains of SF-36.

\section{Acknowledgements}

We gratefully acknowledge all practice staff for their co-operation and support in this study, and all the patients who took part. This project was supported by The State of São Paulo Research Foundation (FAPESP), Brazil (00669-9).

\section{Author details \\ 'Department of Psychiatry, Institute of Psychiatry of Clinics Hospital Faculty of Medicine University of Sao Paulo, (Rua Dr. Ovídio Pires de Campos, 785 - $3^{\circ}$ andar - sala 13), Sao Paulo, (CEP: 05403-010), Brazil. ${ }^{2}$ Division of Psychology, Central Institute of Clinics Hospital Faculty of Medicine University of Sao Paulo, (Rua Dr. Ovídio Pires de Campos, 225. PAMB Térreo), Sao Paulo, (CEP: 05403-000), Brazil. ${ }^{3}$ Department of Preventive Medicine, Faculty of Medicine University of Sao Paulo, (Av. Dr. Arnaldo, $455-2^{\circ}$ andar), Sao Paulo, (CEP: 01246-903), Brazil. ${ }^{4}$ Department of Clinical Medical, Faculty of Medicine University of Sao Paulo, (Av. Dr. Arnaldo, $455-1^{\circ}$ andar - sala 1216), Sao Paulo, (CEP: 01246-903), Brazil. ${ }^{5}$ Department of Clinical Psychology, Institute of Psychology of University of Sao Paulo, (Av. Professor Mello Moraes, 1721 - Bloco F - Cidade Universitária), Sao Paulo, (CEP: 05508-030), Brazil.}

\section{Authors' contributions}

SGH and RF participated in the design of the Prime-MD project, carried out the study, supervised the data collection, and revised the manuscript. MCSL and LSLPCT participated in the design of the Prime-MD project and carried out the project. PRM, MAM and WFG participated in the design of the Prime-MD project, carried out the project, and discussion of results. VDG and BPFS developed the design of the study, developed the rationale of the statistical analysis and drafted the manuscript. All authors read and approved the final manuscript.

\section{Competing interests}

The authors declare that they have no competing interests.

Received: 12 May 2011 Accepted: 25 October 2011

Published: 25 October 2011

\section{References}

1. Ustun TB, Ayuso-Mateos JL, Chatterji S, Mathers C, Murray CJ: Global burden of depressive disorders in the year 2000. Br J Psychiatry 2004, 184:386-392.

2. Cuijpers P, Smit F: Excess mortality in depression: a meta-analysis of community studies. J Affect Disord 2002, 72(3):227-236.

3. King M, Nazareth I, Levy G, Walker C, Morris R, Weich S, Bellon-Saameno JA, Moreno B, Svab I, Rotar D, et al: Prevalence of common mental disorders in general practice attendees across Europe. $\mathrm{Br} J$ Psychiatry 2008, 192(5):362-367.

4. Berardi D, Leggieri G, Ceroni GB, Rucci P, Pezzoli A, Paltrinieri E, Grazian N, Ferrari $\mathrm{G}$ : Depression in primary care. A nationwide epidemiological survey. Fam Pract 2002, 19(4):397-400.

5. Goldberg D, Sharp D, Nanayakkara K: The field trial of the mental disorders section of ICD-10 designed for primary care (ICD10-PHC) in England. Fam Pract 1995, 12(4):466-473.

6. Wells KB, Stewart A, Hays RD, Burnam MA, Rogers W, Daniels M, Berry S, Greenfield S, Ware J: The functioning and well-being of depressed patients. Results from the Medical Outcomes Study. JAMA 1989, 262(7):914-919.

7. Stewart AL, Greenfield S, Hays RD, Wells K, Rogers WH, Berry SD, McGlynn EA, Ware JE Jr: Functional status and well-being of patients with chronic conditions. Results from the Medical Outcomes Study. JAMA 1989, 262(7):907-913.

8. Muller-Tasch T, Peters-Klimm F, Schellberg D, Holzapfel N, Barth A, Junger J, Szecsenyi J, Herzog W: Depression is a major determinant of quality of life in patients with chronic systolic heart failure in general practice. $J$ Card Fail 2007, 13(10):818-824.

9. Thommasen HV, Zhang W: Impact of chronic disease on quality of life in the Bella Coola Valley. Rural Remote Health 2006, 6(2):528.

10. Fortin M, Dubois MF, Hudon C, Soubhi H, Almirall J: Multimorbidity and quality of life: a closer look. Health Qual Life Outcomes 2007, 5:52.

11. Angermeyer MC, Holzinger A, Matschinger $H$, Stengler-Wenzke $K$ : Depression and quality of life: results of a follow-up study. Int J Soc Psychiatry 2002, 48(3):189-199.

12. Angermeyer MC, Matschinger $\mathrm{H}$ : Social distance towards the mentally ill: results of representative surveys in the Federal Republic of Germany. Psychol Med 1997, 27(1):131-141.

13. Dew MA, Bromet EJ, Schulberg HC, Parkinson DK, Curtis EC: Factors affecting service utilization for depression in a white collar population. Soc Psychiatry Psychiatr Epidemiol 1991, 26(5):230-237.

14. Blazer DG, Kessler RC, McGonagle KA, Swartz MS: The prevalence and distribution of major depression in a national community sample: the National Comorbidity Survey. Am J Psychiatry 1994, 151(7):979-986.

15. Lonnqvist J, Sintonen $H$, Syvalahti E, Appelberg B, Koskinen T, Mannikko T, Mehtonen OP, Naarala M, Sihvo S, Auvinen J, et al: Antidepressant efficacy and quality of life in depression: a double-blind study with moclobemide and fluoxetine. Acta Psychiatr Scand 1994, 89(6):363-369.

16. Pyne JM, Patterson TL, Kaplan RM, Gillin JC, Koch WL, Grant I: Assessment of the quality of life of patients with major depression. Psychiatr Serv 1997, 48(2):224-230.

17. Hays RD, Wells KB, Sherbourne CD, Rogers W, Spritzer K: Functioning and well-being outcomes of patients with depression compared with chronic general medical illnesses. Arch Gen Psychiatry 1995, 52(1):11-19.

18. Egede LE: Major depression in individuals with chronic medical disorders: prevalence, correlates and association with health resource utilization, lost productivity and functional disability. Gen Hosp Psychiatry 2007, 29(5):409-416.

19. Katon W, Ciechanowski P: Impact of major depression on chronic medical illness. J Psychosom Res 2002, 53(4):859-863.

20. Rabelo D, Néri A: Bem-estar subjetivo e senso de ajustamento psicológico em idosos que sofreram acidente vascular cerebral: uma revisão. Estudos de Psicologia 2006, 11(2):169-177.

21. Jaracz K, Jaracz J, Kozubski W, Rybakowski JK: Post-stroke quality of life and depression. Acta Neuropsychiatrica 2002, 14(-):219-225.

22. Wang HM, Beyer M, Gensichen J, Gerlach FM: Health-related quality of life among general practice patients with differing chronic diseases in Germany: cross sectional survey. BMC Public Health 2008, 8:246.

23. Whooley MA, Avins AL, Miranda J, Browner WS: Case-finding instruments for depression. Two questions are as good as many. J Gen Intern Med 1997, 12(7):439-445. 
24. Mohr DC, Hart SL, Julian L, Tasch ES: Screening for depression among patients with multiple sclerosis: two questions may be enough. Mult Scler 2007, 13(2):215-219

25. Mitchell AJ, McGlinchey JB, Young D, Chelminski I, Zimmerman M: Accuracy of specific symptoms in the diagnosis of major depressive disorder in psychiatric out-patients: data from the MIDAS project. Psychol Med 2008, 1-10.

26. Lichtman JH, Bigger JT Jr, Blumenthal JA, Frasure-Smith N, Kaufmann PG, Lesperance F, Mark DB, Sheps DS, Taylor CB, Froelicher ES: Depression and coronary heart disease: recommendations for screening, referral, and treatment: a science advisory from the American Heart Association Prevention Committee of the Council on Cardiovascular Nursing, Council on Clinical Cardiology, Council on Epidemiology and Prevention, and Interdisciplinary Council on Quality of Care and Outcomes Research: endorsed by the American Psychiatric Association. Circulation 2008, 118(17):1768-1775.

27. Depression: Management of depression in primary and secondary care. National Clinical Practice Guideline The British Psychological Society \& The Royal College of Psychiatrists; 2004, 53.

28. Henriques SG, Fraguas R, losifescu DV, Menezes PR, Lucia MC, Gattaz WF, Martins MA: Recognition of depressive symptoms by physicians. Clinics (Sao Paulo) 2009, 64(7):629-635.

29. Fraguas R Jr, Henriques SG Jr, De Lucia MS, losifescu DV, Schwartz FH, Menezes PR, Gattaz WF, Martins MA: The detection of depression in medical setting: a study with PRIME-MD. J Affect Disord 2006, 91(1):11-17.

30. Ware JE Jr, Sherbourne CD: The MOS 36-item short-form health survey (SF-36). I. Conceptual framework and item selection. Med Care 1992, 30(6):473-483.

31. Ciconelli RM: Tradução para o português e validação do questionário genérico de avaliação de qualidade de vida "medical outcomes study 36-item short form health survey (SF-36). Escola Paulista de Medicina; 1997.

32. Fleck MP, Lima AF, Louzada S, Schestasky G, Henriques A, Borges VR, Camey S: Association of depressive symptoms and social functioning in primary care service, Brazil. Rev Saude Publica 2002, 36(4):431-438.

33. Huffman JC, Smith FA, Blais MA, Beiser ME, Januzzi JL, Fricchione GL: Rapid screening for major depression in post-myocardial infarction patients: an investigation using Beck Depression Inventory II items. Heart 2006, 92(11):1656-1660.

34. Bonicatto SC, Dew MA, Zaratiegui R, Lorenzo L, Pecina P: Adult outpatients with depression: worse quality of life than in other chronic medical diseases in Argentina. Soc Sci Med 2001, 52(6):911-919.

35. Wells KB, Sherbourne CD: Functioning and utility for current health of patients with depression or chronic medical conditions in managed, primary care practices. Arch Gen Psychiatry 1999, 56(10):897-904.

36. Lam CL, Lauder IJ: The impact of chronic diseases on the health-related quality of life (HRQOL) of Chinese patients in primary care. Fam Pract 2000, 17(2):159-166.

37. Schwenk TL, Coyne JC, Fechner-Bates S: Differences between detected and undetected patients in primary care and depressed psychiatric patients. Gen Hosp Psychiatry 1996, 18(6):407-415.

38. van den Akker M, Buntinx F, Metsemakers JF, Roos S, Knottnerus JA Multimorbidity in general practice: prevalence, incidence, and determinants of co-occurring chronic and recurrent diseases. J Clin Epidemiol 1998, 51(5):367-375.

\section{Pre-publication history}

The pre-publication history for this paper can be accessed here: http://www.biomedcentral.com/1471-2458/11/826/prepub

\section{doi:10.1186/1471-2458-11-826}

Cite this article as: Guajardo et al:: Loss of interest, depressed mood and impact on the quality of life: Cross-sectional survey. BMC Public Health 2011 11:826. 